\title{
Sistem Pengamanan Gudang Senjata menggunakan RFID dan Sidik Jari
}

\author{
Candra Yudianto, Muhammad Rivai, Tasripan \\ Departemen Teknik Elektro, Fakultas Teknologi Elektro, Institut Teknologi Sepuluh Nopember \\ E-mail: yudianto.tc@gmail.com, muhammad_rivai@ee.its.ac.id
}

\begin{abstract}
Abstrak-Pengamanan gudang senjata menjadi bagian penting dari penyelenggaraan pembinaan materiil dalam pelaksanaan tugas Tentara Nasional Indonesia (TNI) Angkatan Udara. Keamanan penyimpanan senjata diperlukan untuk mencegah terjadinya akses masuk ilegal, pencurian dan kehilangan senjata. Saat ini mekanisme pengambilan dan pengembalian senjata dilakukan dengan pencatatan secara manual. Pada penelitian ini dilakukan rancang bangun sistem pengamanan gudang senjata yang menggunakan Radio Frequency Identification (RFID) dan pengenalan sidik jari. Penggunaan RFID memberikan kemudahan dalam mengidentifikasi setiap senjata. Kartu RFID dipasang pada setiap senjata. Tiga buah RFID reader disusun secara paralel untuk mengakomodasi semua akses pintu masuk. Selanjutnya pemindai sidik jari digunakan sebagai pengidentifikasi personil dalam mengakses pintu gudang senjata. Identitas pemilik sidik jari yang terdaftar akan tertampil di LCD. Mikrokontroller Arduino Nano digunakan untuk membaca data dari modul RFID dan sidik jari, menggerakkan solenoid dan membunyikan alarm. Hasil pengujian terhadap penggunaan RFID menunjukkan bahwa jarak maksimum pembacaan kartu RFID senjata adalah sebesar $4 \mathrm{~cm}$. Sedangkan hasil pengujian terhadap pemindai sidik jari memberikan akurasi $100 \%$ dalam pengenalan sidik jari yang telah didaftarkan. Tingkat keberhasilan pengenalan sidik jari juga ditentukan oleh kondisi permukaan ujung jari. Pengujian terhadap keseluruhan sistem menunjukkan hasil bahwa sistem ini dapat berjalan dan berfungsi dengan baik. Hal ini menunjukkan bahwa hasil implementasi sistem telah dapat meningkatkan kinerja sistem pengamanan gudang senjata. Penelitian lebih lanjut diharapkan dapat dikembangkan agar dapat dimonitor secara online melalui sistem informasi pengamanan gudang senjata.
\end{abstract}

Kata Kunci-Gudang senjata, RFID, sidik jari pemindai.

\section{PENDAHULUAN}

$\mathrm{T}$ NI Angkatan Udara merupakan bagian integral dari TNI di mana sebagai komponen utama kekuatan pertahanan negara di udara yang dalam pelaksanaan tugas pokoknya ditentukan oleh efektivitas pelaksanaan pembinaan satuan TNI Angkatan Udara. Penyelenggaraan pembinaan satuan dilaksanakan dalam satu siklus pembinaan secara berkelanjutan meliputi segala aspek yang berpengaruh terhadap pencapaian tugas TNI Angkatan Udara yang dilaksanakan secara terpadu dan terencana meliputi pembinaan organisasi, pembinaan personil, pembinaan materiil, pembinaan pangkalan, pembinaan peranti lunak dan pembinaan latihan. Akan tetapi dalam rangka pelaksanaan pembinaan satuan tersebut masih banyak ditemukan beberapa kendala dan permasalahan yang perlu adanya penanganan secara cepat, berkesinambungan dan dilaksanakan secara berkelanjutan. Permasalahan dalam pembinaan satuan yang tidak segera ditindak lanjuti dengan segera akan dapat "menumpulkan" bahkan "mematikan" kemampuan satuan sehingga pada akhirnya tugas pokok satuan tidak akan pernah tercapai.

\section{DASAR TEORI}

Gudang senjata merupakan tempat penyimpanan senjata, di mana proses penyimpanannya di dalam gedung atau tempat tertutup. Umumnya setiap kesatria atau satuan TNI memiliki satu gedung penyimpanan senjata yang lokasinya terpantau dengan pos penjagaan di satuan tersebut.

RFID (Radio Frequency Identification) adalah sebuah teknologi yang menggunakan komunikasi via gelombang elektromagnetik untuk mengidentifikasi suatu barang atau material. RFID memungkinkan identifikasi dari suatu jarak tanpa perlu memposisikan dengan benar. Hal ini berbeda dengan teknologi identifikasi berbasis barcode [1]. Selain itu tag RFID dapat menampung ID yang yang lebih panjang daripada sistem barcode. Dalam penelitian ini, RFID digunakan untuk identifikasi senjata. RFID menggunakan beberapa jalur gelombang untuk pemancaran sinyal. Namun yang paling banyak dipakai adalah jalur UHF ada frekuensi 865-868MHzz dan 902-928 MHz [2].

Pemindai sidik jari pada dasarnya mengubah informasi biometrik seperti permukaan kulit pada ujung jari menjadi sinyal digital, khususnya citra digital [3]. Identifikasi dan pengenalan sidik jari adalah metode biometris yang secara luas digunakan pada berbagai aplikasi karena keandalan dan akurasinya pada proses mengenali dan memastikan identitas seseorang [4]. Identifikasi dan pengenalan sidik jari adalah metode biometris yang secara luas digunakan pada berbagai aplikasi karena keandalan dan akurasinya pada proses mengenali dan dan memastikan identitas seseorang [2].

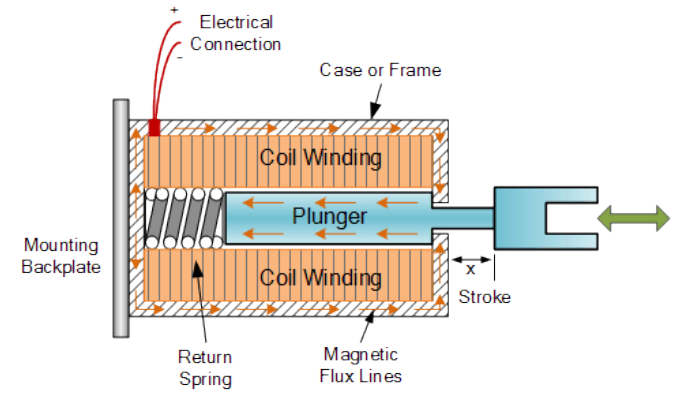

Gambar 1. Mekanisme internal solenoid. 


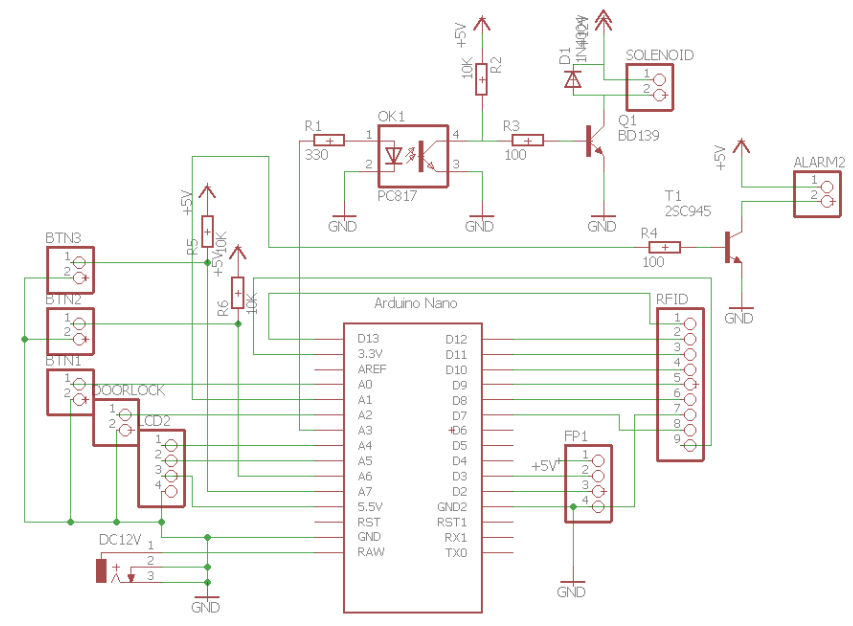

Gambar 2. Skematik Rangkaian Sistem Minimum.

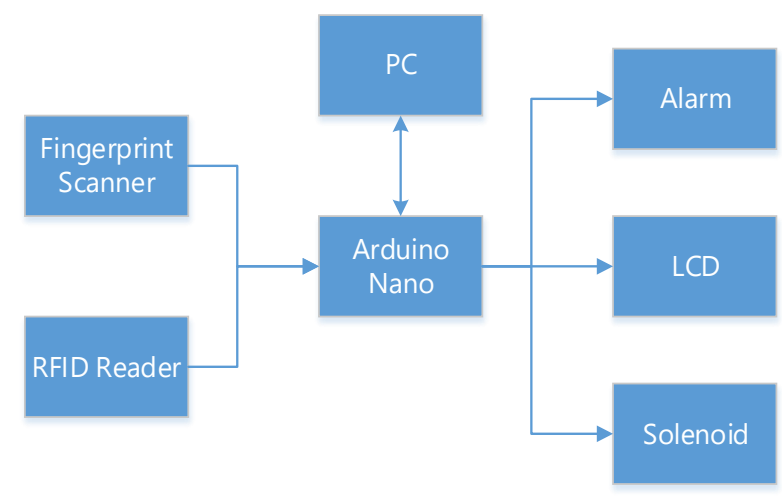

Gambar 3. Blok diagram interkoneksi perangkat.

Solenoid adalah sebuah sistem elektromagnetik yang mana saat kumparannya dialiri listrik maka akan bertindak sebagai magnet [5], ditunjukkan pada Gambar 1. Dalam penelitian sistem ini diaplikasikan untuk mengunci pintu gudang penyimpanan senjata. Solenoid dipilih dibandingkan dengan mekanisme penguncian yang lain karena kemudahan pengaplikasian jika diterapkan pada kondisi sebenarnya yakni di gudang senjata.

\section{PERANCANGAN SISTEM}

Perancangan hardware terdiri dari rangkaian sistem minimum yang menjadi kontrol utama untuk modul sidik jari, modul tag reader, kontrol solenoid, buzzer, dan tampilan LCD. Rangkaian sistem minimum ini digunakan untuk mengintegrasikan keseluruhan sistem. Sistem rangkaian sistem minimum ini juga digunakan untuk menghubungkan Arduino dengan PC untuk sistem monitoring melalui pin serial TX dan RX. Skematik rangkaian sistem minimum yang dirancang, dapat ditunjukkan pada Gambar 2.

Dengan meninjau blok diagram di atas, semua hardware dipasang dan dihubungkan. Pemrosesan seluruh perangkat di atas terjadi pada Arduino Nano. Arduino nano akan membaca input dari sidik jari pemindai dan RFID Reader. Arduino nano dipilih karena ukurannya yang kecil dan jumlah pin I/O yang cukup untuk semua koneksi yang diperlukan.

Sidik jari Pemindai dalam penelitian ini untuk mengidentifikasi personil yang akan mengakses gudang senjata. Sedangkan untuk RFID digunakan untuk mengidentifikasi setiap senjata yang ada di gudang. Dalam penerapannya, setiap perangkat memiliki keuntungan masing-masing. Sidik jari pemindai memungkinkan pengakses gudang senjata hanya orang tertentu yang diberi izin untuk mengakses gudang senjata serta kemungkinan untuk diretas sangat rendah. RFID menggunakan tag yang mempunyai ID unik untuk setiap kartunya sehingga kemungkinan untuk tertukar sangat rendah [6].

Untuk mengunci pintu gudang senjata maka digunakan solenoid. Solenoid akan mengunci pintu saat diberi tegangan. Selain itu untuk memberi peringatan kepada petugas yang berwenang, alarm diterapkan. Alarm akan berbunyi saat adanya personil yang mencoba untuk mengakses sedangkan personil tersebut tidak memiliki hak akses [7].

LCD berguna untuk menampilkan informasi kepada pengguna. Dalam penelitian ini informasi tersebut berupa identitas personil dan status hak akses (diberi atau tidaknya akses masuk ke gudang senjata). LCD pada sistem ini merupakan antarmuka pengguna utama bagi personil yang akan mengakses gudang senjata.

Secara umum, algoritma pada mode pengambilan senjata dijelaskan oleh flowchart pada Gambar 4. Dimulai dari pemilihan mode operasi lalu dilanjutkan dengan pemindaian sidik jari, jika sidik jari yang dipindai sesuai dan dikenali maka solenoid akan membuka dan memberi izin personil untuk masuk. Setelah personil menutup pintu kembali, solenoid akan menutup atau mengunci pintu. Jika personil akan keluar, RFID reader akan memindai ID senjata yang dibawa. Saat ID senjata sesuai dengan ID personil yang mengambil, maka solenoid akan membuka. Saat pintu ditutup, solenoid akan mengunci kembali.

Secara umum, algoritma pada mode pengembalian senjata dijelaskan pada flowchart pada Gambar 5. Pemrosesan mode ini hampir sama dengan mode pengambilan senjata, dimulai dari pemilihan mode operasi lalu dilanjutkan dengan pemindaian sidik jari, jika sidik jari yang dipindai sesuai dan dikenali maka solenoid akan membuka dan memberi izin personil untuk masuk.
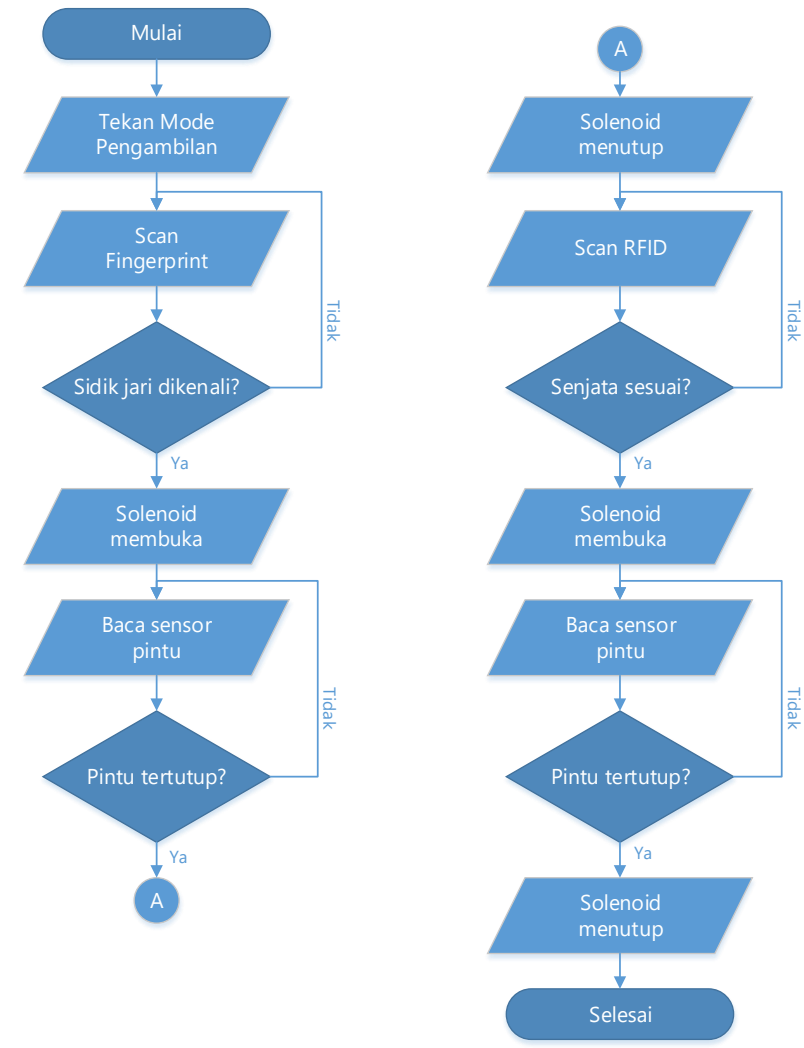

Gambar 4. Flowchart mekanisme pengambilan senjata. 


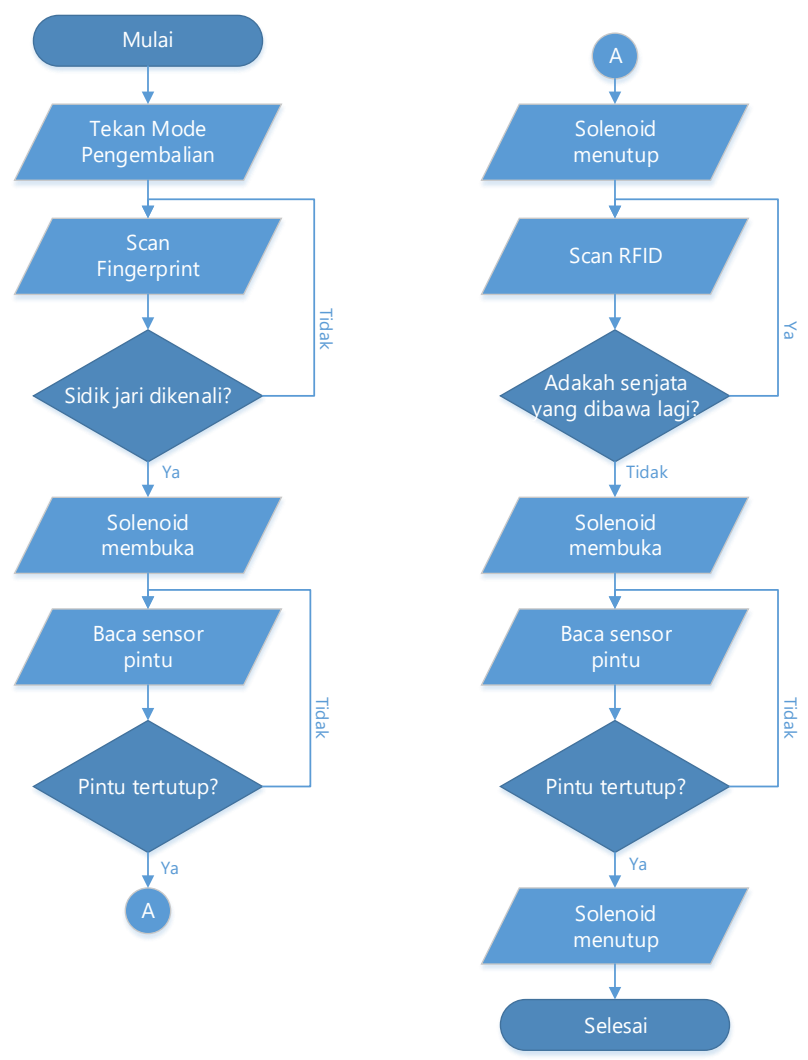

Gambar 5. Flowchart mekanisme pengembalian senjata.

Setelah personil menutup pintu kembali, solenoid akan menutup atau mengunci pintu. Jika personil akan keluar, RFID reader akan memindai apakah ada senjata yang dibawa. Saat tidak ada senjata yang dibawa personil, maka solenoid akan membuka. Saat pintu ditutup, solenoid akan mengunci kembali.

\section{PENGUJIAN DAN ANALISIS}

Pengujian sidik jari ini dilakukan pada 2 tahap. Pengujian pertama menggunakan software yang telah disertakan oleh produsen pemindai sidik jari. Pengujian kedua menggunakan program Arduino. Tujuan dari pengujian ini adalah untuk mengetahui performansi dari sistem pemindai yang digunakan dalam mendeteksi sidik jari.

Pada tahap pengujian dengan Software PC, koneksi antar perangkat dapat digambarkan oleh diagram pada Gambar 5. Dalam pengujian ini, Arduino Nano hanya meneruskan data serial dari pemindai sidik jari ke PC sehingga tidak ada pemrosesan data apapun yang terjadi pada Arduino. Software yang disediakan produsen pemindai sidik jari untuk pengujian ini ditunjukkan pada Gambar 6 .

Pada software ini terdapat dua tombol utama untuk menguji pemindaian sidik jari. Tombol pertama adalah "Enroll". Tombol ini berfungsi untuk menambah data sidik jari yang dapat dikenali. Data sidik jari ini akan tersimpan selamanya pada memori internal pemindai sidik jari. Selanjutnya adalah tombol "Match" yang berfungsi untuk mencocokkan sidik jari yang sudah didaftarkan dengan yang dipindai.

Pengujian pertama dilakukan dengan memindai seluruh jari tangan termasuk jari lain yang tidak didaftarkan. Hasil pengujian tersebut ditunjukkan pada Tabel 1 .

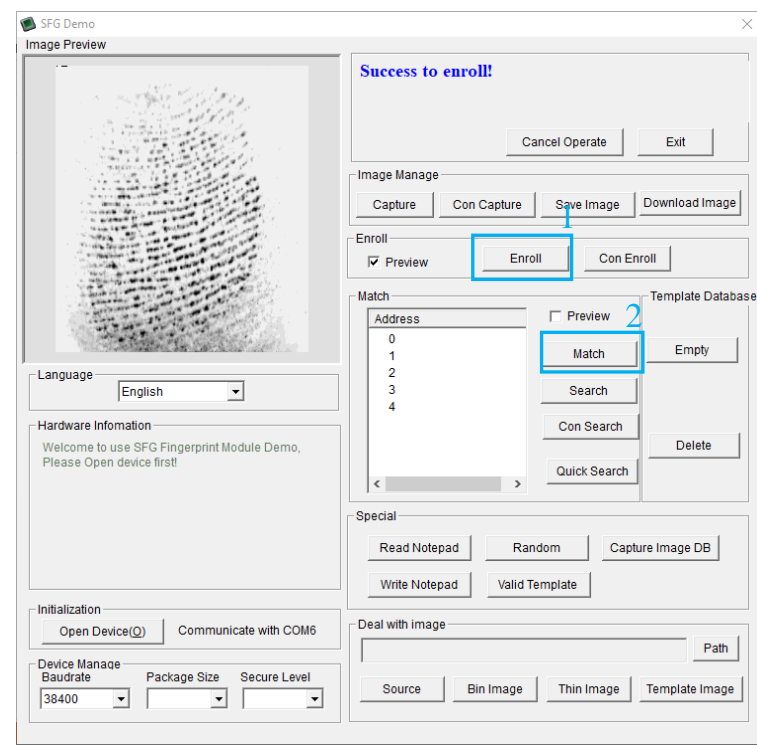

Gambar 6. Software yang disediakan produsen pemindai sidik jari.

Tabel 1.

Pengujian Akurasi Pemindai sidik jari.

\begin{tabular}{lll}
\hline \hline No & Jari & Status \\
\hline 1 & Jempol kanan (terdaftar) & Pass \\
2 & Telunjuk kanan & Fail \\
3 & Jari Tengah kanan & Fail \\
4 & Jari Manis kanan & Fail \\
5 & Kelingking kanan & Fail \\
6 & Jempol kiri & Fail \\
7 & Telunjuk kiri & Fail \\
8 & Jari Tengah kiri & Fail \\
9 & Jari Manis kiri & Fail \\
10 & Kelingking kiri & Fail \\
\hline \hline
\end{tabular}

Tabel 2.

Pengujian pemindai sidik jari terhadap Keadaan Permukaan Ujung Jari

\begin{tabular}{lll}
\hline \hline No & Kondisi Jari & Keberhasilan \\
\hline 1 & Normal & $100 \%$ \\
2 & Basah & $70 \%$ \\
3 & Keriput & $50 \%$ \\
4 & Berminyak & $30 \%$ \\
5 & Kotor & $0 \%$ \\
\hline \hline
\end{tabular}

Dari data pada Tabel 1 didapatkan hasil akurasi pemindaian sidik jari yang tinggi sehingga hanya jari yang didaftarkan saja yang dapat berhasil untuk dikenali. Pengujian selanjutnya merupakan pengujian dengan berbagai kondisi permukaan sidik jari dan ditampilkan pada Tabel 2.

Dari data pada Tabel 2 didapatkan hasil keberhasilan yang tinggi dengan kondisi jari yang normal. Namun kondisi yang lain tetap pada nilai yang cukup baik untuk memindai jari dengan tepat jika disesuaikan dengan kondisi sesungguhnya di lapangan.

Pada tahap pengujian dengan program Arduino, koneksi antar perangkat digambarkan pada Gambar 7. Dalam pengujian ini, prosedur yang dilakukan adalah dengan memasukkan program pembacaan sidik jari pada arduino dan hasilnya ditampilkan pada LCD. Program ini akan memberikan output berupa nilai ID. Data ID tersebut kemudian dikonversi menjadi identitas pemilik ID seperti yang ditunjukkan pada Gambar 8 . 


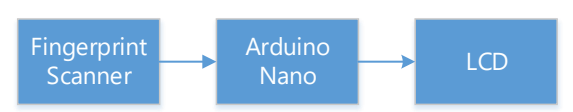

Gambar 7. Diagram blok koneksi perangkat untuk pengujian pemindai sidik jari dengan arduino.

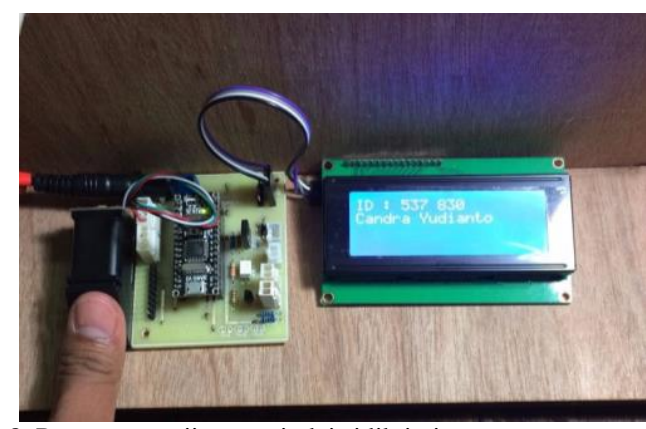

Gambar 8. Proses pengujian pemindai sidik jari.

Pengujian dengan program Arduino menghasilkan output berupa ID sidik jari yang terpindai dengan benar dan nilai "confidence". Nilai "confidence" adalah nilai yang menunjukkan seberapa kepercayaan diri pemindai sidik jari untuk mengenali sidik jari tersebut. Semakin tinggi nilai confidence-nya, maka semakin baik dalam proses mengenali sidik jari. Output pada tahap ini diperlukan untuk proses pemrograman selanjutnya.

Pengujian RFID dilakukan dengan koneksi antar perangkat yang digambarkan oleh diagram blok pada Gambar 9. RFID reader tipe RC-522 yang digunakan dalam penelitian ini menggunakan komunikasi SPI. RFID reader ini selanjutnya diakses Arduino Nano menggunakan program pembacaan RFID sehingga memberikan output data berupa Unique ID kartu. Unique ID ini berbeda-beda setiap kartunya dan mirip dengan sidik jari. Unique ID selanjutnya digunakan sebagai identitas untuk masing-masing senjata.

Selanjutnya diuji jarak kerja maksimal antara reader dan tag. Pengujian dilakukan pada jarak $1 \mathrm{~cm}, 2 \mathrm{~cm}, 3 \mathrm{~cm}, 4 \mathrm{~cm}$, dan $5 \mathrm{~cm}$ dari RFID reader. Dari hasil pengujian yang dilakukan, seperti yang ditunjukkan pada Tabel 3, didapatkan hasil bahwa jarak maksimum reader dengan tag agar dapat terbaca adalah sebesar $4 \mathrm{~cm}$. Sehingga untuk mengakomodasi semua akses pintu masuk dengan lebar 10 $\mathrm{cm}$ dibutuhkan setidaknya 3 buah reader, seperti yang ditunjukkan pada Gambar 10.

Dari hasil pengujian didapatkan hasil bahwa ketiga reader yang disusun secara paralel pada pintu gudang senjata, dapat bekerja saling melengkapi dalam range pendeteksian yang telah ditentukan.

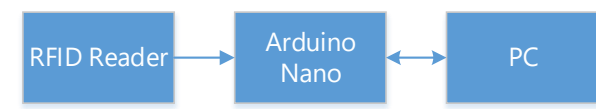

Gambar 9. Diagram blok koneksi perangkat dalam pengujian RFID.

Tabel 3.

Pengujian RFID pada Berbagai Ukuran Jarak Antara Reader dan Tag RFID

\begin{tabular}{lll}
\hline \hline No & $\begin{array}{l}\text { Jarak antara reader } \text { dan } \\
\text { tag RFID }\end{array}$ & Deteksi tag RFID \\
\hline 1 & $1 \mathrm{~cm}$ & Terdeteksi \\
2 & $2 \mathrm{~cm}$ & Terdeteksi \\
3 & $3 \mathrm{~cm}$ & Terdeteksi \\
4 & $4 \mathrm{~cm}$ & Terdeteksi \\
5 & $5 \mathrm{~cm}$ & Tidak Terdeteksi \\
\hline \hline
\end{tabular}

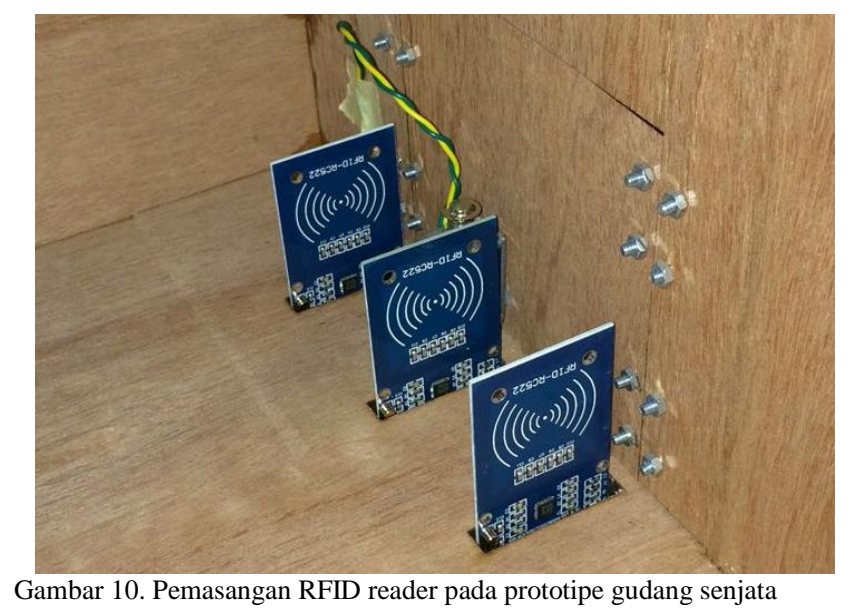

Pengujian aktuator dalam hal ini adalah solenoid dan alarm. Masing-masing perangkat aktuator memiliki driver agar dapat sistem dapat bekerja dengan baik dan tidak merusak Arduino Nano. Solenoid dan alarm yang digunakan bekerja pada tegangan $12 \mathrm{Vdc}$ sedangkan output dari Arduino hanya 5Vdc. Pengujian aktuator ini ditujukan untuk mengetahui keberhasilan sistem kerja dari rangkaian driver solenoid dan driver alarm yang telah dirancang.

Berdasarkan Gambar 2, solenoid akan bekerja saat Arduino memberikan logic Low atau 0. Pengujian solenoid dilakukan dengan memberikan pulsa keluaran digital high/low yang dihasilkan dengan menggunakan kode pemrograman Arduino. Berdasarkan Gambar 2, pengaktifan alarm dilakukan dengan memberikan logika high pada driver alarm. Logika high dihasilkan dengan memberikan pulsa keluaran digital $5 \mathrm{~V}$ dari Arduino, sehingga dihasilkan arus yang melewati resistor dan memicu basis transistor. Antara kolektor dan emitor transistor akan dihasilkan nilai impedansi yang rendah dan akan menyalakan alarm. Hasil pengujian terhadap solenoid dapat ditunjukkan pada Tabel 4. Sedangkan hasil pengujian terhadap alarm dapat ditunjukkan pada Tabel 5.

Dari hasil pengujian yang telah dilakukan dapat diketahui bahwa saat Arduino Nano menghasilkan tegangan pulsa low sebesar $0 \mathrm{~V}$, maka akan dihasilkan tegangan keluaran $11.92 \mathrm{~V}$ dan solenoid menjadi aktif, begitu juga sebaliknya. Sedangkan pada pengujian alarm, saat sinyal keluaran berupa pulsa high, maka dihasilkan tegangan keluaran $4.95 \mathrm{~V}$ dan alarm menjadi aktif. Dari kedua pengujian, dapat diketahui bahwa driver solenoid dan driver alarm dapat berfungsi dengan baik.

Tabel 4.

Pengujian Solenoid.

\begin{tabular}{|c|c|c|c|}
\hline $\begin{array}{l}\text { Sinyal } \\
\text { Keluaran }\end{array}$ & $\begin{array}{l}\text { Vout pada } \\
\text { Arduino } \\
\text { (Volt) }\end{array}$ & $\begin{array}{l}\text { Vout pada } \\
\text { solenoid } \\
\text { (Volt) }\end{array}$ & $\begin{array}{l}\text { Kondisi } \\
\text { Solenoid }\end{array}$ \\
\hline Low & 0 & 11.92 & Aktif \\
\hline High & 5 & 0 & Tidak Aktif \\
\hline
\end{tabular}

Tabel 5.

Pengujian Alarm.

\begin{tabular}{|c|c|c|c|}
\hline $\begin{array}{l}\text { Sinyal } \\
\text { Keluaran }\end{array}$ & $\begin{array}{l}\text { Vout pada } \\
\text { Arduino } \\
\text { (Volt) }\end{array}$ & $\begin{array}{l}\text { Vout pada } \\
\text { alarm (Volt) }\end{array}$ & $\begin{array}{l}\text { Kondisi } \\
\text { Solenoid }\end{array}$ \\
\hline Low & 0 & 0 & Tidak Aktif \\
\hline High & 5 & 4.95 & Aktif \\
\hline
\end{tabular}


Pengujian secara keseluruhan sistim ini dilakukan dengan memasang semua perangkat, membuat program sesuai yang dibutuhkan, kemudian dijalankan dan dicatat tingkat keberhasilannya. Proses pengujian dilakukan pada proses pengambilan senjata dan pengembalian senjata. Pada proses pengambilan senjata, dilakukan pemilihan mode pengambilan senjata dilakukan dengan menekan tombol "Pengambilan". Setelah dilakukan pemilihan mode, maka dilanjutkan dengan pemindaian sidik jari. Identitas dari sidik jari yang sudah terdaftar akan tampil di LCD. Jika sidik jari yang dipindai sesuai dan dikenali maka solenoid menjadi aktif dan pintu terbuka. Kemudian solenoid kembali ke kondisi semula dan pintu tertutup. Sebelum membuka pintu gudang senjata kembali, ID senjata didata dengan membaca tag yang terpasang pada senjata terhadap RFID reader yang terpasang di dekat pintu gudang senjata. Ketika ID senjata sudah sesuai dengan ID personil anggota, maka solenoid menjadi aktif dan pintu terbuka kembali. Kemudian solenoid kembali ke kondisi semua dan pintu gudang senjata akan tertutup kembali. Ketika ID senjata pada tag RFID dibaca oleh RFID reader dan tidak sesuai dengan identitas personil anggota, maka pintu gudang tidak akan terbuka. Jika dalam tiga kali kesempatan, baik pada proses pemindaian sidik jari maupun pada proses pembacaan tag RFID, maka alarm buzzer akan berbunyi.

Pada proses pengembalian senjata, dilakukan pemilihan mode pengembalian senjata dilakukan dengan menekan tombol "Pengembalian". Setelah dilakukan pemilihan mode, maka dilanjutkan dengan pemindaian sidik jari. Identitas dari sidik jari yang sudah terdaftar akan tampil di LCD. Jika sidik jari yang dipindai sesuai dan dikenali maka solenoid menjadi aktif dan pintu terbuka. Kemudian solenoid kembali ke kondisi semula dan pintu tertutup. Sebelum keluar dari gudang senjata, ID senjata, yang akan dikembalikan, didata dengan membaca tag yang terpasang pada senjata terhadap RFID reader yang terpasang di dekat pintu gudang senjata. Proses tersebut dilakukan sampai tidak ada lagi senjata yang dibawa. Kemudian solenoid menjadi aktif dan pintu terbuka kembali. Kemudian solenoid kembali ke kondisi semula dan pintu gudang senjata akan tertutup kembali.

Dari hasil pengujian sistem yang telah dirancang, dapat ditunjukkan bahwa proses pemindaian sidik jari dengan menggunakan pemindai sidik jari telah dapat dilakukan dengan baik. Setiap sidik jari yang telah didaftarkan, mampu tertampil pada LCD, identitas dari pemilik sidik jari. Selain itu pintu gudang senjata juga ikut terbuka, yang menandakan solenoid mampu bekerja dengan baik. Ketika proses keluar dari gudang senjata, tag RFID yang terpasang pada senjata dapat dibaca oleh RFID reader dengan baik dan pintu gudang senjata terbuka. Hal tersebut menandakan bahwa solenoid telah dapat bekerja dengan baik, dan sistem keamanan yang telah dirancang dapat berfungsi dengan baik. Di mana ID senjata yang sesuai dengan ID personil anggota akan menyebabkan pintu gudang senjata terbuka, dan terjadinya ketidaksesuaian sidik jari dan ketidaksesuaian ID senjata sebanyak tiga kali kesempatan, akan menyebabkan alarm buzzer berbunyi.

\section{KESIMPULAN}

Pada penelitian ini telah dibuat sistem pengamanan gudang senjata secara elektronik. Sistem ini terdiri dari Radio Frequency Identification (RFID) dan pengenalan sidik jari. Penggunaan RFID memberikan kemudahan dalam mengidentifikasi setiap senjata. Kartu RFID dipasang pada setiap senjata. Tiga buah RFID reader disusun secara paralel untuk mengakomodasi semua akses pintu masuk. Sedangkan pemindaian sidik jari dengan pemindai sidik jari digunakan sebagai pengidentifikasi personil dalam mengakses pintu gudang senjata. Identitas pemilik sidik jari yang terdaftar akan tertampil di LCD. Mikrokontroller Arduino Nano digunakan untuk membaca data dari modul RFID dan sidik jari, menggerakkan solenoid dan membunyikan alarm. Hasil pengujian terhadap penggunaan RFID menunjukkan bahwa jarak maksimum pembacaan kartu RFID senjata adalah sebesar $4 \mathrm{~cm}$. Sedangkan hasil pengujian terhadap pemindai sidik jari memberikan akurasi $100 \%$ dalam pengenalan sidik jari yang telah didaftarkan. Tingkat keberhasilan pengenalan sidik jari juga ditentukan oleh kondisi permukaan ujung jari. Pengujian terhadap keseluruhan sistem menunjukkan hasil bahwa sistem ini dapat berjalan dan berfungsi dengan baik. Hal ini menunjukkan bahwa hasil implementasi sistem telah dapat meningkatkan kinerja sistem pengamanan gudang senjata.

\section{DAFTAR PUSTAKA}

[1] R. Want, “An Introduction to RFID Technology,” IEEE Pervasive Comput., vol. 5, no. 1, pp. 25-33, 2006.

[2] and S. V. S. Swaraj, R. R. Khandelwal, "RFID Based Automatic Vehicle Identification for Access Control," Int. J. Innov. Res. Comput. Commun. Eng., vol. 4, no. 2, p. 2016, 2016.

[3] V. I. and J. Baras, "Authentication of fingerprint scanners," IEEE Int. Conf. Acoust. Speech Signal Process., 2011.

[4] S. M. and M. N. S. Nath, P. Banerjee, R. Biswas, "Arduino based door unlocking system with real time control," 2016 2nd Int. Conf. Contemp. Comput. Informatics, 2016.

[5] P. S. and J. P. Y. Park, "Smart digital door lock for the home automation," in TENCON 2009 - 2009 IEEE Region 10 Conference, 2009.

[6] M. R. AH. Yesa, "Otomasi Pelayanan Binatu Berbasis Raspberry $\mathrm{Pi}$ untuk Meningkatkan Efisiensi Kegiatan Operasional dan Pelayanan Binatu," J. Tenik ITS, vol. 5, no. 2, 2016.

[7] dan S. N. A. Syahid, M. Rivai, "Sistem Keamanan pada Lingkungan Pondok Pesantren Menggunakan Raspberry Pi," $J$. Tenik ITS, vol. 5, no. 2, 2016. 